\title{
Precautionary Procedures in Basrah Oil Fields Drilling Operations Using Smartphones
}

Ibrahim Abdul-Salam Salih ${ }^{*}$, Prof. Dr. Mohammed Saleh Aljawad*, Dr. Bashar Saadoon Mahdi** *Petroleum Technology Department / University of Technology

${ }^{* *}$ Computer Sciences Department / University of Technology

\begin{abstract}
الخلاصة
حقول النفط فى محافظة البصرة يتم حفر ها مع مواجهة صعوبات كونها تحمل مشاكل متعددة، وهذه المشاكل يتم حلها عادة بشكل غير و افي. عدم الكفائة في الاجرائات الخاصة بالتعامل مع مشاكل الحفر عادة يؤدي الى زيادة بالوقت اللازم لحل لحل المشكلة. هذه الدراسة تهدف الى توفير افضل اجرائات وقائية التي يمكن اتخاذها بشكل تطبيق يعمل على الهو اتف الذكية (تحت اسم (Precautions Enhancer لتوفير احتياطيات جديرة بالثقة عند الحاجة باي مكان في الحقل النفطي.

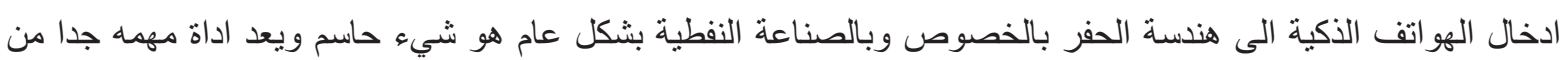
المكن تطوير ها لتوفير دقة اعلى وسر عة في التعامل مع المشاكل داخل الحقل.

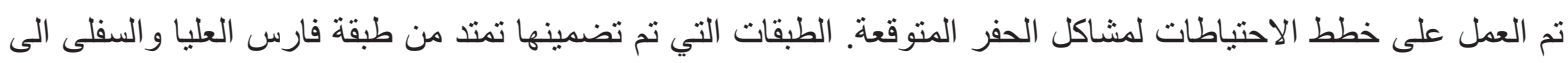
طبقة المِشرف. الاحتباطات التي تم وضعها كافضل اجر ائات مبنية على اساس الخبرات الحقلية ومناهج ال IWCF القياسية. التقنيات البرمجية المستخدمة هي: تقنية الخوارزمية المبوبة نوع (forward) لتعزيز قدرات (Precautions Enhancer) لتجنب المشاكل البرمجية . التطبيق Precautions Enhancer (PE) يحمل واجة مستخدم ودية وسهلة الاستخدام، ومن الممكن استخدامه في الحقول حيث تم بنائه باستخدام قو اعد بيانات لمشاكل الحقول محمية بشكل كامل اضافة الى الاحتياطات مع مشاكل الحفر لحقول البصرة النفطية؛ كل مشاكل الحفر التي من الممكن مواجهتهه خلال عملية الحفر مع الاجرائات الاحتياطية اللازمة تم اضافتهه لقاعدة بيانات البرنامج. الكلمات الدالة الاحتياطات، مشاكل الحفر ، الهو اتف الذكية.
\end{abstract}

\section{$\underline{\text { Abstract }}$}

Basrah oil fields carry multiple drilling problems that are drilled with difficulty, these problems are often treated incompetently. This inefficiency in the procedures in handling the problems often results in a long wait around time. This study aims to offer the best precautionary procedures that can be taken in the form of a smartphone's application (Precautions Enhancer) to reach trustworthy precautions anywhere needed on the oil field. 
The introduction of smartphones to the drilling engineering in particular and the petroleum industry in general is a critical and a very useful tool that could be developed to gain accuracy and speed on field.

The plans of precautions for the expected drilling problems are carried out. The included formations extend from the upper and lower Faris to Mishrif. The precautions that are set as the best practice are based on field experience and standardized IWCF methods. The used programming techniques are: the classify algorithm (forward) technique is used to enhance Precautions Enhancer's (PE) abilities to avoid the problems.

An application called Precautions Enhancer (PE) having a friendly user interface that can be used in the field is built with a full secure database of the fields' problems and precautions with a database of the drilling problems in Basra oil fields in PE; all of the drilling problems that could encountered while drilling with their precautionary procedures are all mounted in the database of PE.

Keywords Precautions, drilling problems, smartphones.

\section{$\underline{\text { Introduction }}$}

In Basrah oil fields, since the exploration of the first field, drilling problems have been encountered on a regular basis. The encountering of these problems wasn't occasionally successful, and in some cases, the drilling team faced greater complications. The drilling problems varied widely, there were bit balling problems, tight hole, slow ROP, formations with water content that may flow into the well, lost circulation, and so on.

\section{Programming design and implementation}

The applied programming features used in building PE application are the following:

1. The Java programming language is a general-purpose, simultaneous, class-based, objectoriented language. [6] Java is the programming language that was used to program PE.

2. Android Studio is collaboration between JetBrains and Google. Android Studio is built a top JetBrain's IntelliJ, and so its functionality is a superset of IntelliJ. [7] It is the environment used to program $\mathrm{PE}$, in which many programming features were employed. 
3. Classify algorithm (forward) technique the forward method simply refers to the classification type from which it starts from the input data to the output data. [8]

4. The database: The application contains a database that consists of texts. These texts are connected to PE by an ID submitted to each partition that is needed to be used.

The algorithm (figure A-1) that is used in coding PE is as follows:

- The first step is the beginning of the algorithm.

- The second step is the selection of the user's governorate, the field, the formation, the problem. In which the user should specify the kind of problem that is expected ahead in order to prepare appropriately.

- The third step is the comparison between the selected data and the database to achieve the results.

- The fourth step is getting the matched data from the comparison of the previous step.

- The fifth step is showing the user the results.

- The sixth step is offering the user the additional help such as kill sheets, stuck pipe worksheet, extra equations. If needed, go to the needed section.

- The seventh step is ending the algorithm.

\section{Area of Study}

The fields that are taken into consideration in this study are the following:

1. Rumaila Oil Field: The field is found $50 \mathrm{~km}$ toward the west of the city of Basra, southern Iraq, and some $30 \mathrm{~km}$ to the west of the Zubair field. [1]

2. Zubair Oil Field: This is an oil field located in southern Iraq, approximately $20 \mathrm{~km}$ south-west of Basra. [2]

3. West Qurna 1 Oil Field: It is an oil field, located $50 \mathrm{~km}$ northwest of the city of Basra, and overlaps the northern edge of the Rumaila field. [3]

4. West Qurna 2 Oil Field: It is situated in the southern Iraqi part, 65 kilometers north-west of Basra, and it is one of the world's largest fields. [4] 


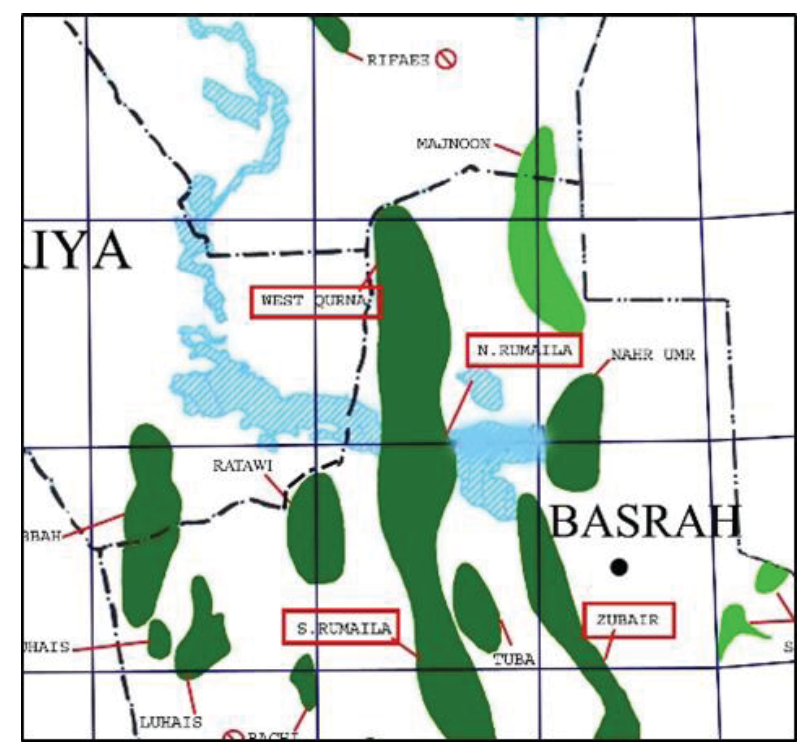

Fig. (1) A geographical map of all the Iraqi Oil Fields showing the oil fields. ${ }^{[5]}$

\section{Basra Oil Fields' Problems}

Each formation will be discussed, individually, and comprehensively while presenting all the supporting evidence that came to sight. The formations are:

1. Upper and Lower Faris formation: It consists mainly of limestone and claystone interbedded by few layers of gypsum (impermeable zones). Some hydrocarbons of small percentages have been spotted in some fields. The expected problems in this formation are:

a. Tight holes due to the rock composition, the claystone or shale will be pressurized, causing the hole to collapse.

b. Bit balling which is faced due to the presence of the claystone which has a tendency to adhere to the bit causing this problem.

c. Slow ROP will be encountered in case the bit balling problem wasn't treated adequately.

d. Gas cut mud has been recorded in this formation, so it should be kept in mind if encountered, due to the hydrocarbons presence.

2. Dammam formation: it consists primarily of dolomite and limestone that contains many fractures. 
a. Mud loss is highly likely possible to happen here, due to the vuggy structure of the dolomite, and at the bottom of the formation total mud loss is probable. Thus, blind drilling might be needed to drill the bottom section of the formation.

b. In some cases, it has been noticed that tight hole problems have been encountered due to the improper hole sweeping that was performed by the drilling crew in addition to the presence of limestone which is a big contributor to the tight hole problem.

3. Umm-Er-Radhuma: it consists of mainly two types of rocks; dolomite with streaks of anhydrite and dolomitic limestone (and shale in some fields). The problems that were noticed in this formation are the following:

a. Due to the presence of the dolomite in the top, so some seepages are probable to be happening. Dolomite is a very vuggy rock and it is originated from Limestone due to the ion exchange.

b. It is of maximum importance to note that only partial sever losses are recorded in West Qurna 2 oil field at the top of this formation and this is due to a fault that was noticed in that field.

c. Differential sticking is probable due to the high permeability of this formation, especially when running the casing in hole.

d. Tight hole due to thick mud cake. This is also caused by the permeable beds of dolomite at the top of the formation.

e. Tight hole due to swelling. It is caused because of the argillaceous beds at the bottom of the formation that are expected to swell.

4. Tayarat formation: It is composed of bituminous shale at the top of the formation, dolomite, compact limestone and some marl at the bottom. It is not a problematic zone in itself. Though it will become the worst formation when the hydrostatic balance is lost, due to the presence of a very active water aquifer almost in the middle. This water has some $\mathrm{H}_{2} \mathrm{~S}$ and the concentration of this $\mathrm{H}_{2} \mathrm{~S}$ is not constant in Iraqi oil fields.

5. Shiranish formation: This formation is formed mainly of argillaceous limestone with some marl at the top of the formation. The expected problems are:

a. Bit balling may occur due to the presence of argillaceous limestone, leading to slow ROP especially at top of the formation. 
b. Tight hole is also expected due to swelling of the Marl at the top of this formation (swelling is coming either from the absorption of water or due to pore pressure). Tight hole will be faced later on (during pulling the string out of the hole for short trip or to change the bit).

6. Hartha formation: It is mainly composed of sequences of dolomite, limestone and some marl at the top. Afterwards limestone and argillaceous limestone are dispersed throughout the rest of the formation. The expected problems in this formation are:

a. Mud loss: Losses are expected in this formation due to the vugs and pores present in the top of the formation.

b. Tight hole: This problem may occur due to the presence of streaks of marl.

7. Sadi formation: It is composed of mainly limestone of different characteristics. Limestone and argillaceous limestone are the types found in this formation (some marly limestone and chalky limestone have been noticed as well). It is the first formation in this section which contains the most important pay zones in south of Iraq.

Gas cut mud on surface could be noticed during drilling the reservoir, obviously due to the presence of the hydrocarbons.

8. Tanuma formation: This section is composed of mainly thick beds of shale and some limestone.

Since this formation is composed of shale beds, there are many problems that are potentially dangerous, if not encountered on delicate properties, that can outcome the possible problems of the shale, such as, hole washout, excessive water invasion, the pipe sticking is highly probable in here, and sloughing could be encountered. Each of these problems carry a special property for reencountering to avoid it efficiently.

9. Khasib formation: It mainly composes of limestone and a few argillaceous limestone interbedded by shale layers.

The only problem that has been encountered here is the differential sticking so leaving the string static is very risky.

10. Mishrif formation: In general, Mishrif is composed of limestone of different characteristics with weak to good oil impregnation, and some shale layers at the top, and some interbedded in the middle of the formation. Thus, tight holes and stuck pipe problems are expected here. In addition to the subnormal pressure due to the production and depletion of the reservoir. This 


\section{No.20 Journal of Petroleum Research \& Studies}

\section{(JPR\&S)}

depletion of the reservoir will encounter a low formation pressure, whilst the drilling mud weight must be kept high enough to restrain the fluids in the overlying formations from entering the well, which will cause differential sticking.

\section{Precautionary procedures}

The precautionary procedures for each formation are discussed in this section.

1. Upper and lower Faris formation: The precautions that are needed to avoid the bit balling problem are:

a. Minimizing of the WOB.

b. Usage of maximum RPM that can be provided.

c. Increase of the mud weight.

d. Addition of a lubricant to the mud and anti-bit balling material.

e. Applying the maximum flow rate that can be provided.

Slow ROP can be avoided by applying the following precautions:

a. Making sure that the proper type of mud ( $\mathrm{KCl}$ polymer) is being used.

b. Checking the mud properties, and ensuring that they are as written in the program. The most important property to check for is the filtrate.

c. Use of proper bit design with proper down hole equipment.

To avoid tight holes, simple procedures could be taken:

a. Reaming up and down each stand.

b. Pumping $5 \mathrm{~m} 3$ of high viscosity pill every (two-three) connections will be helpful.

These tight hole precautionary procedures have been noticed in some of the drilling reports obtained from West Qurna, Rumaila and Zubair, and no records of tight holes have been recorded there when these procedures were taken.

Gas cut mud has been recorded in this formation, so it should be kept in mind if encountered.

2. Dammam formation: The needed preparations include:

a. Collecting enough water in the water pit and in the tank to be used for drilling. Coordination with the office should be of highest priority.

b. Start drilling the previous casing shoe with minimum mud weight (normally is $1.08 \mathrm{sg}$ ). 


\section{No.20 Journal of Petroleum Research \& Studies}

\section{(JPR\&S)}

c. Top of the thief zone is about 130 meters from top of Dammam, it is a matter of few hours in drilling until it's reached. The top of Dammam is very soft, so ROP with modern tools can reach $50 \mathrm{~m} / \mathrm{hr}$, therefore the drilling crew should be ready for mixing mud transfer, and for pumping water.

d. Drilling should be stopped 10 meters above the expected thief zone, the hole should be swept with $10 \mathrm{~m} 3$ of high viscosity mud pill for vertical wells, and low and high viscosity pills for deviated wells, while keeping the pipe in up and down motion. This sweeping for the hole is very important to avoid pipe sticking due to annulus loading with cuttings.

In some cases, in Rumaila field, tight hole problem has been noticed in this formation, due to the improper hole sweeping mentioned earlier in the precautions.

3. Umm-Er-Radhuma formation: There are a few certain procedures that could be taken to minimize the risk of facing these problems. They are:

1) Controlling the ROP at the top of this formation about $(20-25 \mathrm{~m} / \mathrm{hr})$ is very useful in avoiding the problem of losses.

2) To prevent differential sticking, we need to minimize the seven conditions that lead to differential sticking. Most of the conditions cannot be controlled, so we must focus on the ones that can:

a. Permeable formations: Case off permeable zones and avoid long open hole sections.

b. Overbalance: Try limiting it by controlling the mud weight and circulating the cuttings out of the vertical section before making any connection.

c. Filter cake: If flocculation is observed, it should be chemically treated. Chemical additives such as thinners, lubricants, and deformable colloids will help condition the cake to lower the coefficient of friction and the thickness of the cake.

d. Wall contact: Usage of spiral drill collars is recommended in here.

e. Static pipe: If the risk of differential sticking is high, static time should be avoided until the risk is reduced.

f. Time: Minimizing connection time is very important.

g. Side loads: Long, heavy BHAs in high angles of inclination will cause high drag and impart a large side load on the lower side of the hole. 
3) Short wiper trip is highly recommended here. This will wash out the thick mud cake and keep the hole in gauge. Also, the internal mud cake inside the formation will help in sealing the formation.

4) To avoid the swelling of the clay in the Argillaceous Limestone, it is highly recommended to add a lubricant to the mud, this will also minimize the stuck pipe incidents and increase the chances of freeing the pipe, in addition to lubrication.

4. Tayarat formation: There are no special procedures that needs to be followed. By controlling the hydrostatic pressure, it will be sufficient to pass this formation safely, and continue drilling ahead.

5. Shiranish formation: The precautions that should be taken before entering this formation are the following:

a. For bit balling: Adding a lubricant to the mud before entering this formation. Lubricants will also enhance the mud cake, and minimize the swelling. Making the mud inhibitive is better by using $\mathrm{KCl}$ polymer mud.

b. Using as much as possible of flow rate will keep the bit clean, also high RPM, and minimum WOB are advised.

c. If any over pull, or tight hole is noticed during the pulling or lowering of the drill string, then the MW needs to be increased, and from field experience $(+/-0.03 \mathrm{ppg})$ will be helpful in overcoming the over pull.

6. Hartha formation: Precautionary measurements that needs to be followed before entering the formation are:

a. The hole should be circulated clean and the mud conditioned, the mud weight should be as low as possible without losing the balance.

b. The rheological properties (YP, and VP) should be at the lowest acceptable limit.

c. POOH for short wiper trip to the last point of trip or to casing shoe. This will wash out the mud cake, clean the annulus, and lift all the cuttings, which may make some pack off in the hole, causing some surge pressure in the section.

d. When drilling is started again, and after breaking the gel. Top of Hartha needs to be drilled with minimum Parameters that can be provided, till at least the first 25 meters TVD are drilled, 
and then the hole is circulated clean and $\mathrm{POOH}$ for short wiper trip till top of Hartha, to clean the well from the cuttings.

e. RIH back again and drilling starts again, while increasing the parameters gradually.

If the losses are expected in the field, then proper preparations should be taken, in order to face any losses when they occur:

a. Enough mud needs to be prepared so that drilling blindly as much as needed is possible. Low and High Viscosity pills needs to be prepared also to be pumped at the end of each joint or stand to push the cuttings away from the bit during a connection.

b. The procedures above need to be followed for the short wiper trip as well, those will minimize the risk of stuck pipe in case of complete losses happened.

7. Sadi formation: The precautionary measurements should be taken to drill the formation safely are:

a. The BOPS and other related equipment must be tested and acknowledged working after RIH casing, and prior to drilling this formation (in this section oil/gas kick are expected here).

b. Mud weight must be controlled according to the program.

c. ROP has to be controlled, to minimize the gas slag in the mud (because the cuttings will be less).

d. Connection time should be minimized. IWCF procedures should be followed for this case.

e. The hole must be kept filled during tripping.

f. Poor boy degasser or vacuum degasser are Very important to deal with gas cut mud.

g. To avoid the damage to the reservoir, Calcium Carbonate as weighing materials can be used.

8. Tanuma formation: The needed specifications to drill this formation safely are as follows:

a. Minimizing the flow rate when entering this formation will minimize the wash out.

b. Usage of a drilling fluid of salinity higher than the shale is important. Tanuma's salinity is 67,000 ppm so using mud of salinity higher than that will be very useful.

c. Using $\mathrm{KCl}$ mud, Potassium is the best ion in closing the plate of shale and stopping water from invading the shale platelets.

d. Using a filtrate loss agent will stop the invasion of water, and mud, inside the formation through micro fracture and fractures. 
e. Using a Lubricant is also very helpful in minimizing the losses, and freeing stuck is much easier when it's used.

f. Increasing the mud weight a little bit is advised, if any sloughing of shale is noticed. The shape of the cuttings can help in determining if pressurized shale is being drilled.

g. Minimizing the thickness of shale that is exposed to drilling environment is important.

h. Better to use the smallest motor for this section and the least bend, in this case, the hammering on the wall of the hole can be minimized. Minimizing the circulating time or flow rate during reaming time, before connection, will be very helpful in case of motor usage.

i. Using a perforated Non Return Valve (NRV) near the bit is very important, to release the pressure from the string during pack off.

j. After drilling Tanuma, and reaching the bottom of Khasib, circulating for two bottoms up, and performing short wiper trip to the previous casing shoe is advised. It is recommended to $\mathrm{POOH}$ slowly with slow flow rate, and low RPM, through the formation especially when a directional hole is being drilled.

9. Khasib formation: The only problem that has been encountered here is the differential sticking so leaving the string static is very risky.

To prevent differential sticking, we need to minimize the seven conditions that lead to differential sticking. Most of the conditions cannot be controlled, so we must focus on the ones that can.

a. Permeable formations: Case off permeable zones and avoid long open hole sections.

b. Overbalance: Try limiting it by controlling the mud weight and circulating the cuttings out of the vertical section before making any connection.

c. Filter cake: If flocculation is observed, it should be chemically treated. Chemical additives such as thinners, lubricants, and deformable colloids will help condition the cake to lower the coefficient of friction and the thickness of the cake.

d. Wall contact: Smaller tubulars and larger hole size will give less wall contact.

e. Static pipe: If the risk of differential sticking is high, static time should be avoided until the risk is reduced.

f. Time: The quicker pipe movement and circulation are re-established, the less likely we are to get stuck. If we are stuck, we must quickly take the correct first action to prevent further sticking. 
g. Side loads: Long, heavy BHAs in high angles of inclination will cause high drag and impart a large side load on the low side of the hole.

Also, drilling with Calcium Carbonate as weighing materials is highly recommended.

10. Mishrif formation: The actions that must be taken to contain the well from undergoing the mentioned problems are:

1) It is highly recommended to keep the pumps on as long as possible, and switching them off should be as low as possible. Also, it is beneficial to circulate enough to keep the shale in place before making a connection.

2) Before entering Mishrif, the mud tank should be checked that it's filled with mud.

3) To avoid differential sticking:

a. Connection time must be minimized.

b. The string must be kept under rotation, even with slow RPM.

\section{Case study}

During the drilling process in Rumaila oil field, when Umm-Er-Radhuma formation was being drilled, several tight hole incidents were encountered due to the swelling of the formation, each of which was treated by reaming the tight spot up and down.

From field experience, gathered data, and standardized IWCF procedures, it was concluded that by using PE as follows:

1. Starting the application as in figure (A-2).

2. Choosing the field (Rumaila) as in figure (A-3).

3. Choosing the formation (Umm-Er-Radhuma) as in figure (A-4).

4. Choosing the required problem's precautions as in figure (A-5).

5. Figure A-6 will present the necessary precautionary procedures needed to be followed in order to avoid the expected problem.

By that, the optimum precautionary procedures are presented to avoid the expected problem in the formation which can be followed by the drilling team in which it recommends "It is recommended to add a lubricant to the mud, this will minimize also the stuck pipe incidents and increase the chances of freeing the pipe, in addition to lubrication". 


\section{Conclusions}

- An application called Precautions Enhancer (PE) is successfully built and functioning on android operating system smartphones.

- The application is mounted in PE with the fields (Rumaila, West-Qurna 1, West-Qurna 2, and Zubair) and their relevant formations including all the expected problems from Faris to Mishrif.

- Precautionary procedures to avoid the expected problems in each formation drilled are all mounted safely in the database of PE.

- Tanuma and Mishrif need the highest level of precautions to drill safely.

\section{Abbreviations}

$\begin{array}{ll}\text { RPM } & \text { :Round Per Minute } \\ \text { BHA } & \text { :Bottom Hole Assembly } \\ \text { POOH } & \text { :Pull Out Of Hole } \\ \text { IWCF } & \text { :International Well Control Forum } \\ \text { RIH } & \text { :Run In Hole } \\ \text { BOP } & \text { :Blow Out Preventers } \\ \text { TVD } & \text { :True Vertical Depth } \\ \text { YP } & : Y i e l d \text { Point } \\ \text { VP } & : \text { Plastic Viscosity } \\ \text { MW } & \text { :Mud Weight } \\ \text { WOB } & : \text { Weight On Bit } \\ \text { ROP } & \text { :Rate Of Penetration }\end{array}$




\section{$\underline{\text { References }}$}

1. M. a.-J. D. A.-S. W.J. Mohammed, "Reservoir Flow Simulation Study for a Sector in Main Pay-South Rumaila Oil Field," in SPE Oil and Gas Conference and Exhibition, Mumbai, 2010.

2. "Hydrocarbons technology," Kable, 2017. [Online]. Available: http://www.hydrocarbons-technology.com.

3. L. A.-H. H. Q. Sami El-Halfawi, "Achieving Excellence in Well Completion Projects in Iraq's South Oil Fields," in SPE/IADC, 2011.

4. [4] M. P. S. A. a. D. M. Anastasia Vedernikova, "Overcoming Challenges in the West Qurna-2 Drilling Campaign," in SPE/IADC, 2016.

5. M. o. Oil, "Iraq Map," Ministery of Oil, Baghdad, 2015.

6. B. J. G. S. G. B. a. A. B. James Gosling, The Java Language Specification, California: Oracle, 1997.

7. C. C. Adam Gerber, Learn Android Studio, Apress, 2013.

8. S. B.-D. Shai Shalev-Shwartz, Understanding Machine Learning: From Theory to Algorithms, Cambridge University Press, 2014.

9. Java, Java Security Overview, Sun Microsystems Inc., 2005.

\section{Appendix A}

\section{Algorithm 1: Precautionary and Treatment Measurements} Algorithm

Step 1: Begin.

Step 2: Select the Governorate/Field/Formation/Problem.

Step 3: Compare the input data with the database.

Step 4: Get the needed information from the database.

Step 5: The required data will be shown on the program.

Step 6: If additional help needed, transmit to the desired help section.

Step 7: End.

Fig. (A-1) Algorithm of Precautions Enhancer. 


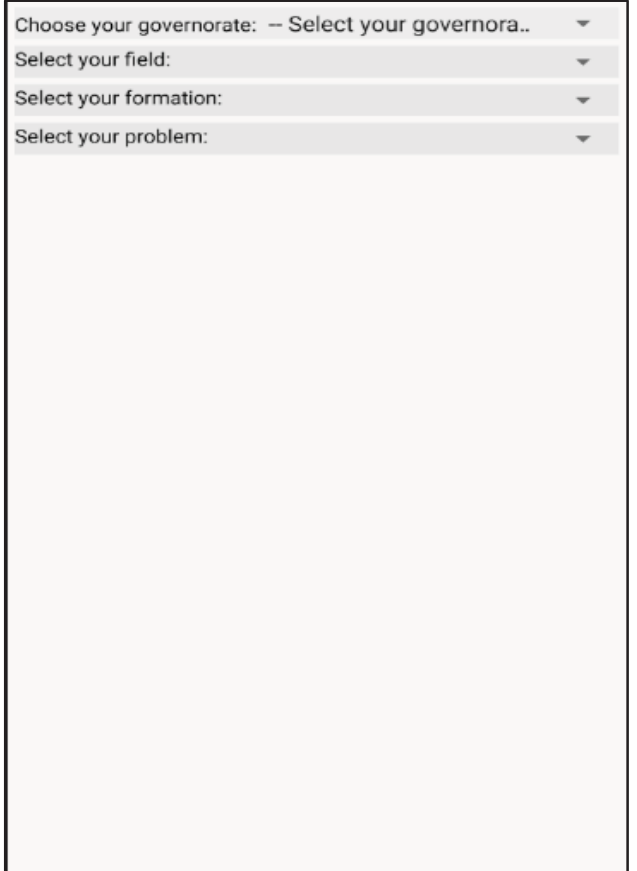

Fig. (A-2) Main window of Precautions Enhancer.

\begin{tabular}{|l|l|}
\hline Choose your governorate: Basrah & - \\
Select your field: Rumaila & \\
Select your formation: & - Select your formation- \\
Select your problem: & Upper and lower Faris \\
& Dammam \\
& Em Uraduma \\
& Tayarat \\
& Shiranish \\
& Hartha \\
& Saadi \\
& Tanuma \\
& Khasib \\
& Mishrif \\
\hline
\end{tabular}

Fig. (A-4) Choosing the required formation.

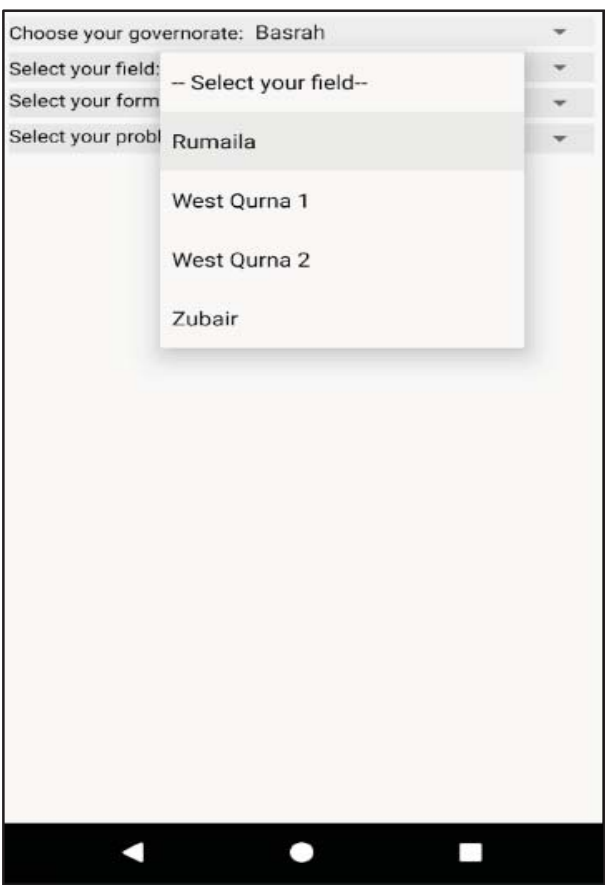

Fig. (A-3) Choosing the required field.

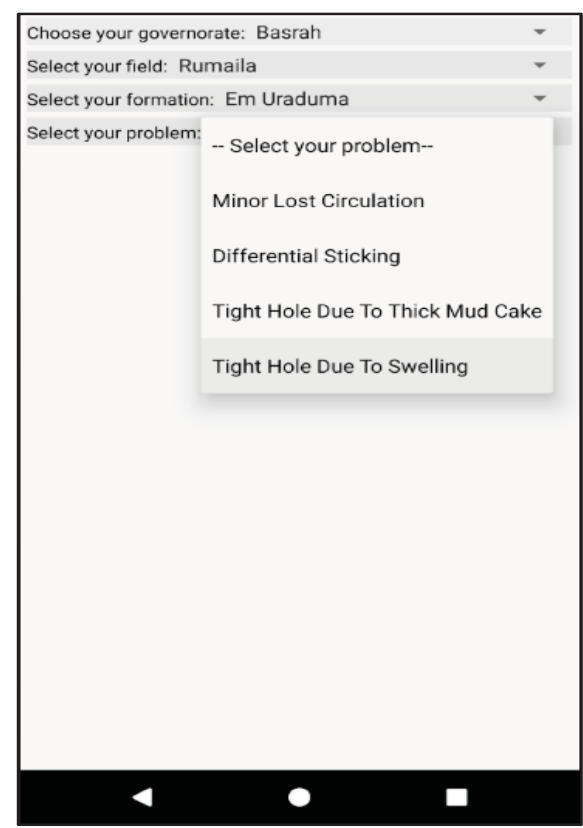

Fig. (A-5) Choosing the expected problem needed to be avoided. 


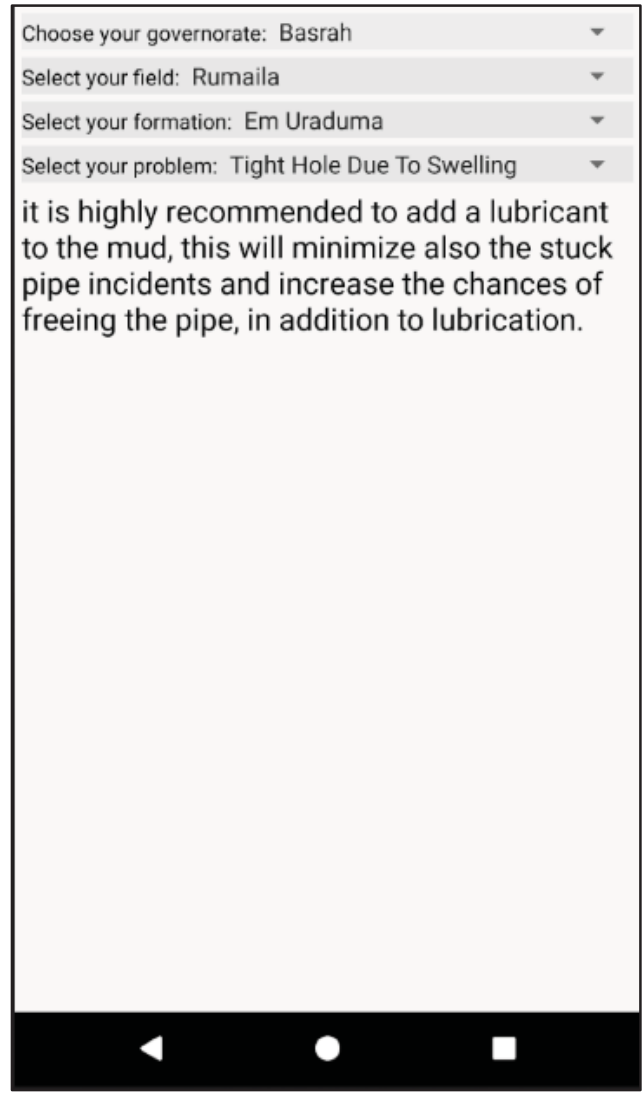

Fig. (A-6) Presenting the proposed instructions by Precautions Enhancer. 